governmental organizations in self-help schemes and in drafting appropriate legislation. Similarly, scientific exchange and the sharing of equipment and monitoring schemes should begin to harmonize environmental reporting over the next decade. For all this, one must be impressed at the rapidity of movement.

But the scale of environmental devastation in Eastern Europe is enormous, with as much as one-fifth of inhabited areas seriously polluted to the point of cutting short the life expectancy of up to half the children. The possibility of full recovery is slim, at least until collectively we recognize that in environmental renaissance there is the scope for economic recovery that could put whole nations back to work. Peace and environmental transformation go hand in hand. It is always wise to remember that global environmental management is not a stand-alone issue. All these books, in their fascinating ways, reveal this essential but sobering truth.

Timothy O'Riordan is in the Centre for Social and Economic Research into the Global Environment, University of East Anglia, Norwich, Norfolk NR4 7TJ, UK.

\section{Of two minds}

H. J. Eysenck

Wolfgang Paull und C. G. Jung: Ein Briefwechsel, 1932-1958. Edited by C. A. Meier. Springer. Pp. 275. DM98.

THIS collection of letters in German is a curious book, just as the association between an outstanding scientist such as Pauli and a mystic such as Jung is rather curious. The association came about because of Pauli's apparent need for treatment, although it is never very clear what exactly he was suffering from. Pauli sometimes regards Jung as a leader in the field of psychology, and a natural scientist (Naturwissenschaftler), rather than a Geisteswissenschaftler, but it is difficult to understand how he could make such an error. Freud at least tried to abide by the rules of science, although not very successfully; Jung never bothered, and retained the mantle of 'guru' and mystic right to the end. All his work is impressionistic and anecdotal; there is no attempt at rigorous statement of hypotheses, deduction of testable consequences and empirical proof or disproof. Jung simply stated his views about such things as the "collective unconscious", regarding them as facts simply on the grounds of ipse dixit. $\mathrm{He}$ was miles removed from orthodox psychology, and has only a small but devoted group of followers,

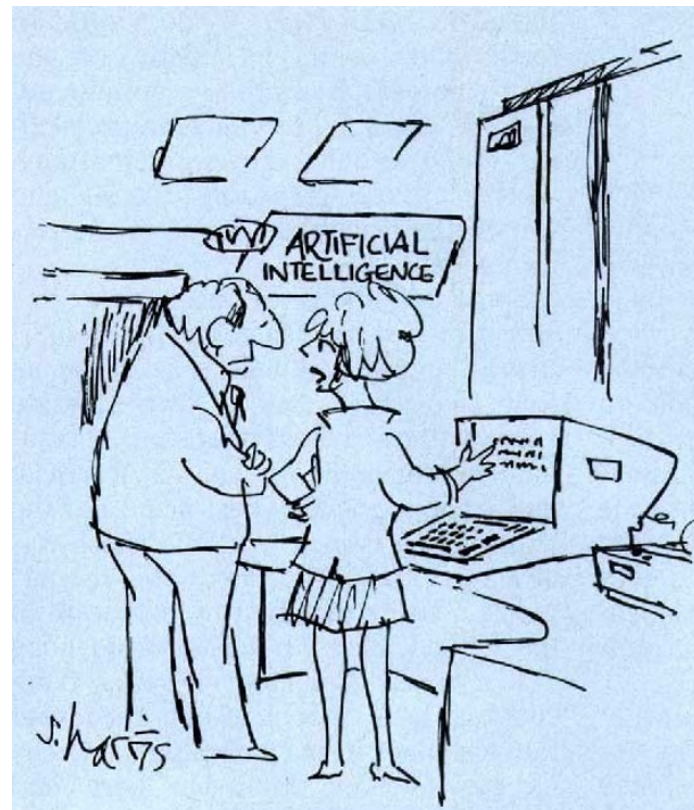

Scientists and science come under fire once again In Sidney Harris's latest collection of cartoons. From Personal Ads to Cloning Labs Is publlshed In paperback by $W$. H. Freeman, £8.95, \$10.95.

"It's beginning to show some human characteristics - faulty reasoning, forgetfulness and repetition."

few if any trained in psychology.

Pauli noted some interesting things that might have made him suspicious. Thus he reports in one of his letters that as the analysis proceeded, more and more Jungian symbols appeared in his dreams; he failed to realize that he was just being trained to dream Jungian dreams! He also indulged in dream interpretation; when he dreamed of a wasp with differently coloured stripes he told Jung that it typified the dual aspect of his personality. So much for science. In turn Jung told him that UFOs were the "projected", that is, concretized symbolism of the process of individuation. Pauli never asked if any meaning was attached to such a statement or whether there could be any form of proof.

Pauli certainly followed Jung's teaching, and attempted to support some of his ideas by reference to physical theories. Thus he argued that the principle of complementarity presented a fundamental analogy to the notion of 'consciousness' and 'unconsciousness'. $\mathrm{He}$ also considered that for a unified understanding of nature it was necessary to go back to the archaic backgrounds of natural science; he mentions Kepler, to whom the Copernican system appeared as a symbol of the Holy Trinity.

Quite generally, there is a curious attempt to find analogies between psychological concepts and physical laws. Jung followed suit, but seems to have exaggerated the analogy dreadfully. Thus he misstates the Heisenberg principle ("that which is observed is a disturbance produced by the observation") and concludes that "if one looks long enough into a dark hole, one perceives what it is that does the looking", which he then identifies with the fundamental principle of Yoga. All of this leads to a justification of clairvoyance and precognition! Thus a very remote analogy from physics is used to justify parapsychological phenomena, whose existence are taken for granted. The whole letter should be read to give an insight into the cognitive world of a mystic (pages 11-12). How Pauli came to argue that Jung was a leader in natural science and psychology passes understanding.

Most readers will find it difficult to understand much of what Jung says, or even to imagine ways of testing it experimentally. Pauli's approbation reminds me of Newton's excursions into alchemy, or his disquisition about ' 666 ' and the nature of the beast in the Bible, a curious aberration that even psychologists find difficult to explain. But then even supremely intelligent people commit imbecilities when removed from their proper field - the Webbs visited the Soviet Union and said: "We have seen the future, and it works!"; Bertrand Russell called Kennedy "more wicked than Hitler" when he stood up to Khrushchev, and later advocated a nuclear strike by the West against Russia. This particular aberration may serve as a clinical document, but it will not change Pauli's great scientific achievement, nor will it serve to shore up Jung's vanishing reputation. Its main effect will be to demonstrate to readers the vagaries of a great mind.

H. J. Eysenck is at the Institute of Psychiatry, De Crespigny Park, Denmark Hill, London SE5 8AF, UK. 